\title{
Poroid Hidradenoma: Case Report and Excision Rationale
}

\author{
J. Arwyn-Jones*, N. O’Hara, A. De Leo, J. Birch \\ Department of Plastic Surgery, Oxford University Hospitals Trust, Oxford, UK \\ Email: "james.arwyn-jones@seh.ox.ac.uk \\ Received 16 February 2016; accepted 11 April 2016; published 14 April 2016 \\ Copyright (C) 2016 by authors and Scientific Research Publishing Inc. \\ This work is licensed under the Creative Commons Attribution International License (CC BY). \\ http://creativecommons.org/licenses/by/4.0/

c) (†) Open Access

\begin{abstract}
Poroid hidradenoma is a benign eccrine neoplasm of the poroma family. We report a 65-year-old male patient who presented to his general practitioner with a poroid hidradenoma in zone 2 of the flexor surface of his left middle finger. Diagnosis was confirmed histologically, after which the patient was referred to us for wider excision. Although poroid hidradenoma is a benign tumour, wide local excision is mandatory. Here we discuss the reasoning behind this and present a rationale for excision margins.
\end{abstract}

\section{Keywords}

Poroma, Poroid Hidradenoma, Eccrine Tumour/Neoplasm

\section{Introduction}

Poromas are typically benign sweat gland neoplasms that account for $10 \%$ of sudoriferous tumours, which themselves represent around 1\% of primary skin lesions [1]. Since the first report by Pinkus et al. in 1956, poromas were separated into 3 distinct subtypes:

- Hidroacanthoma simplex,

- Classic (eccrine) poroma,

- Dermal duct tumour.

In 1990, Abenoza and Ackerman put forward the addition of a fourth member to this poroma family-poroid hidradenoma [2]. This is an uncommon, benign neoplasm with eccrine differentiation, so-called because it is a hybrid lesion with morphology intermediate between a poroma and a hidradenoma [3].

All variants of poroid neoplasms have similar cellular components, characterized by the presence of poroid and cuticular cells, with monomorphism of their nuclei and ductal differentiation presenting as intracytoplasmic

${ }^{*}$ Corresponding author. 
or intercellular vacuolization. They are set apart from each other by their location within the epidermis or dermis, and additional distinctive histological features:

- Hidroacanthoma simplex - neoplastic poroid cells are confined entirely within the epidermis arranged in ovoid nests.

- Eccrine poroma-neoplastic poroid cells involve the basal layer of the epidermis and extend into the superficial dermis.

- Dermal duct tumour - neoplastic poroid cells are restricted to the dermis in the form of discrete nodules that are widely spaced and devoid of cysts.

- When the neoplastic poroid and cuticular cells (i.e. features of a poroid neosplasm) are in a tumour with solid and cystic components, all within the dermis without connection to the epidermis (i.e. features of a hidradenoma), the neoplasm is called poroid hidradenoma [4].

In this report, we present an overview of poroid hidradenoma and a case demonstrating a typical presentation and management pathway. We present this rare case to add to the limited number of reports, and offer reasoning for current management. The ultimate treatment of poroid hidradenoma, as in our case, is wide local excision with a $4 \mathrm{~mm}$ margin. We suggest a hypothesis for this, as yet to be described in the current literature.

\section{Background}

Typically, poroid hidradenoma presents as a solitary, well circumscribed, occasionally tender, intradermal papule or nodule, with a diameter ranging from 1 to $2 \mathrm{~cm}$. It usually appears slightly reddish but may rarely be pigmented or bluish. Eccrine sweat glands are found on virtually all skin surfaces, but they most densely populate the palmar and plantar surfaces as well as the head. In keeping with this, the most common sites of poroid hidradenoma involvement are the head and neck regions, with a tendency towards the centro-facial region (about $85 \%$ of cases). Less frequent sites include the axilla, trunk and extremities. One paper reported a case of vulvar poroid hidradenoma, leading the authors to agree with others in that there is no true site of predilection for this rare tumour [5] [6].

Case reports have identified the lesion in patients aged from 13 through to 97 years, though poroid hidradenoma shows a peak of incidence in the sixth decade [7] [8]. Some authors have reported approximately equal incidence in male and female patients [9], but we would suggest that poroid hidradenoma may have a higher incidence in men, as there have been more cases reported in males (see Table 1). Liu et al. found no cases of poroid hidradenoma in females in their studies in Taiwan [1] [4], but the authors attributed this to the fact that their hospital population is predominantly male veterans. In 2001, Cho et al. postulated that poroid hidradenoma may have a predilection for the Asian (Japanese \& Korean) population, as at the time of their writing, they added a fourth Asian (Korean) patient to the literature of twelve cases of poroid hidradenoma in total reported before $2002[10]$.

Since the publication of Cho et al. there have been 19 reported cases of poroid hidradenoma, with 15 males and 4 females. There were 8 Asian patients, 3 white patients, and 8 further patients in whom ethnicity was not specified.

More recent reports have focussed on the epidemiology and methods of diagnosing poroid hidradenoma, but there have been no clear rationales for treatment of this neoplasm. Here, we consider the approach to excision of these neoplasms and provide a supporting hypothesis.

\section{The Case}

A 65-year-old male presented to his general practitioner with a palpable lesion in zone 2 of the flexor surface of his left middle finger, just distal to the proximal interphalangeal joint. Family history and past medical history were not significant. The lesion appeared two years earlier, but the patient presented now because it was becoming sore during his work as a gas-heating engineer.

Physical examination revealed a tender, $11 \times 9 \mathrm{~mm}$, soft, movable tumefaction, separate from and lateral to the flexor tendon, with clinically distinct margins. The lesion was covered by apparently normal skin. At first it was clinically suspected as being a sebaceous cyst, and after excision by the general practitioner was sent for histopathological examination.

On macroscopic inspection the lesion was an irregular fibrous and membranous piece of tissue measuring $11 \times 9 \times 2 \mathrm{~mm}$. Histological examination revealed a disrupted adnexal neoplasm made up of both solid and 
Table 1. The case reports of poroid hidradenoma in male and female patients.

\begin{tabular}{|c|c|c|c|c|}
\hline Case report & Patient gender & Patient age (yrs) & Patient ethnicity & Lesion location \\
\hline Alowami et al. 2002 [6] & $\mathrm{F}$ & 46 & Unknown & $\mathrm{R}$ labia majora \\
\hline \multirow[t]{3}{*}{ Monteagudo et al. 2005 [11] } & $\mathrm{F}$ & 74 & Unknown & L buttock \\
\hline & M & 78 & Asian & L cheek \\
\hline & M & 64 & Asian & Scalp \\
\hline \multirow{4}{*}{ Chen et al. 2006 [1] } & M & 45 & Asian & L temporal \\
\hline & M & 64 & Asian & $\mathrm{R}$ chest \\
\hline & M & 65 & Asian & Abdomen \\
\hline & M & 69 & Asian & R buttock \\
\hline Ueno et al. 2007 [12] & M & 34 & Asian & L leg (anterior) \\
\hline \multirow[t]{2}{*}{ Delfino et al. 2007 [13] } & M & 35 & Unknown & $\mathrm{R}$ thigh (posterior) \\
\hline & $\mathrm{F}$ & 43 & Unknown & Scalp \\
\hline \multirow[t]{2}{*}{ Kazakov et al. 2008 [14] } & M & 63 & Unknown & Hand \\
\hline & M & 78 & Unknown & Scalp \\
\hline Chiu et al. 2008 [15] & $\mathrm{F}$ & 55 & Asian & Upper back \\
\hline Piana et al. 2010 [16] & M & 70 & White & Thigh \\
\hline Lopez et al. 2011 [8] & M & 13 & White & $\mathrm{R}$ forearm \\
\hline Goksugar et al. 2011 [17] & M & 65 & White & L buttock \\
\hline Mlika et al. 2012 [9] & M & 81 & Unknown & Presternal \\
\hline Dravid et al. 2014 [5] & M & 34 & Unknown & $\mathrm{R}$ chest \\
\hline
\end{tabular}

cystic components, composed of multiple papillary structures with large stalks, surrounded by a zone of compressed connective tissue. At high magnification, the neoplasm appeared to be composed of multiple papillae, with a mixed population of large eosinophilic cuticular cells and monomorphous poroid cells. The lesion was confined to the dermis, with no connection to the overlying epidermis-confirming the diagnosis of poroid hidradenoma.

The patient was therefore referred to our department for a wider, $4 \mathrm{~mm}$ excision. A $22 \times 5 \times 3 \mathrm{~mm}$ elliptical excision was performed. The histological picture described was that of acral skin with scar tissue only. The patient was discharged, and at 9 month follow-up remains recurrence-free.

\subsection{Differential Diagnosis}

The main clinical differential diagnoses of poroid hidradenoma are other poromas-i.e. hidroacanthoma simplex, dermal duct tumour, eccrine poroma, apocrine hidradenoma. Some benign subcutaneous connective tissue neoplasms such as fibroma, fibrolipoma, dermatofibroma, epidermal inclusion cyst and basal cell epithelioma may also be challenging differentials, causing confusion with poroid hidradenoma [7] [18]. Even malignant eccrine poroma presents similarly. Indeed, clinical impression pre-operatively is rarely correct [1] [7], and histological examination of tissue samples is key to diagnostic certainty. Despite clinical similarities, treatment of poroid hidradenoma differs from that of other similar skin lesions (discussed below), hence the importance of clear diagnosis. There are also reports of the value of fine needle aspiration cytology in the diagnosis of cutaneous lesions-especially in cases with cyst formation [5] [16].

\subsection{Treatment}

Our patient presented in a typical fashion, whereby a small lesion is removed by a general practitioner with 2 $\mathrm{mm}$ margins as a benign skin lesion. When histology confirms the diagnosis of poroid hidradenoma, the surgical 
team are usually invited to perform a 4mm wide local excision of the lesion to the fascia layer, and reconstruction is often needed. Yearly follow-up is recommended for the first 2 years.

\section{Discussion}

\subsection{Malignant Potential}

Poroid hidradenoma is usually a solitary neoplasm, and is benign, though its histological characteristics may resemble those of malignant neoplasms, often causing diagnostic uncertainty [9]. This uncertainty makes thorough histological examination and immunohistochemical profiling mandatory in order to establish the correct diagnosis. Despite being a benign neoplasm, malignant transformation of poroid hidradenoma is thought possible, and several reports have suggested a $1 \%$ malignant transformation rate [5] [13], but there have been no reports of confirmed malignancy in cases of poroid hidradenoma. The prognosis of this neoplasm is very good, and recurrence has been reported in only one case [19].

We posit that this $1 \%$ risk suggested by previous authors may be attributed to two known phenomena. Firstly, that these neoplasms are histologically very similar to eccrine poromas, for which cases of malignant transformation are well described. Secondly, that these neoplasms have been reported to coexist within the same lesion as other poromas with known malignant potential [1] [15], hence the risk of a lesion becoming malignant is real. The rarity of these neoplasms makes exact rates difficult to calculate.

\subsection{Excision Rationale}

There has been little focus in previous reports on the rationale behind excision margins. We suggest that given its similarity to malignant lesions, poroid hidradenoma should be treated as any skin malignancy. As such, poroid hidradenoma requires surgical treatment that includes radical excision of the lesion with a $4 \mathrm{~mm}$ margin in order to minimize risk of recurrence or malignant transformation, as a matter of precaution. As for other skin malignancies, the excision should be to the fascia layer.

\section{Conclusions}

Poroid hidradenoma is an increasingly recognised neoplasm, with more cases being reported across the globe, and diagnostic techniques successful in setting it apart from other members of the poroma family. We have reviewed previous case reports in the literature to provide some background information about this neoplasm, and presented our own case showing typical features.

It has been mentioned in many previous reports that poroid hidradenoma has a malignant transformation rate of $1 \%$, but little evidence to support this. We agree that a risk of malignant transformation does exist, given the nature of poroid hidradenoma, with its similarities to eccrine poromas and potential concurrence with other neoplasms. We believe there to be insufficient evidence to suggest an absolute value.

There has also been little discussion of the management of poroid hidradenoma. Given its hypothesized malignant potential, we suggest it should be treated as for other skin malignancies, with radical excision with a 4 $\mathrm{mm}$ margin down to the fascia layer, and yearly follow up for 2 years thereafter.

As more cases are reported, it will be interesting and valuable to gain more information about the epidemiological features of poroid hidradenoma, and in following up patients-rates of recurrence and/or malignant transformation.

\section{Conflicts of Interest}

The authors declare that they have no conflicts of Interest.

\section{Funding}

None.

\section{References}

[1] Chen, C.C., Change, Y.T. and Liu, H.N. (2006) Clinical and Histological Characteristics of Poroid Neoplasms: A 
Study of 25 Cases in Taiwan. International Journal of Dermatology, 45, 722-727. http://dx.doi.org/10.1111/j.1365-4632.2006.02741.x

[2] Abenoza, P. and Ackerman, A.B. (1990) Poromas. Neoplasms with Eccrine Differentiation. Lea \& Febiger, Philadelphia, 113-185.

[3] Requena, L. and Sanchez, M. (1992) Poroid Hidradenoma: A Light Microscopic and Immunohistochemical Study. Cutis, 50, 43-46.

[4] Liu, H.N., Chang, Y.T., Chen, C.C. and Huang, C.H. (2006) Histopathological and Immunohistochemical Studies of Poroid Hidradenoma. Archives of Dermatological Research, 297, 319-323. http://dx.doi.org/10.1007/s00403-005-0606-4

[5] Dravid, N.V., Gadre, A.S., Damle, R.P., Bagale, P.S. and Suryawanshi, K.H. (2014) Papillary Poroid Hidradenoma: A Distinct Histopathological Entity-A Rare Case Report. Journal of Clinical and Diagnostic Research, 8, 138-139.

[6] Alowami, S.O., Malik, A. and Hanna, W. (2002) Vulvar Poroid Hidradenoma. American Journal of Dermatopathology, 24, 523-525. http://dx.doi.org/10.1097/00000372-200212000-00016

[7] Battistella, M., Langbein, L., Peltre, B. and Cribier, B. (2010) From Hidroacanthoma Simplex to Poroid Hidradenoma: Clinicopathologic and Immunohistochemic Study of Poroid Neoplasms and Reappraisal of Their Histogenesis. American Journal of Dermatopathology, 32, 459-468. http://dx.doi.org/10.1097/DAD.0b013e3181bc91ff

[8] López, V., Santonja, N., Calduch-Rodríguez, L. and Jordá, E. (2011) Poroid Hidradenoma in a Child: An Unusual Presentation. Pediatric Dermatology, 28, 60-61. http://dx.doi.org/10.1111/j.1525-1470.2010.01359.x

[9] Mlika, M., Chelly, B., Ayadi-Kaddour, A., Boudaya, S., Kilani, T. and El Mezni, F. (2012) Poroid Hidradenoma: A Case Report. Our Dermatology Online, 3, 43-45.

[10] Cho, S., Kim, J.S., Shin, J.H., Kim, J.H., Kim, H.J., Whang, K.K. and Hahm, J.H. (2001) Poroid Hidradenoma. International Journal of Dermatology, 40, 62-64. http://dx.doi.org/10.1046/j.1365-4362.2001.01067-6.x

[11] Monteagudo, B., Iglesias, B., de la Torre, C., Paredes, C., Vázquez-Blanco, M., Ginarte, M. and Labandeira, J. (2005) Poroid Hidradenoma. Actas Dermo-Sifiliográficas, 96, 398-399. http://dx.doi.org/10.1016/S0001-7310(05)73100-8

[12] Ueno, T., Mitsuishi, T. and Kawana, S. (2007) Poroid Hidradenoma: A Case Report with Review of Japanese Published Work. Journal of Dermatology, 34, 495-497. http://dx.doi.org/10.1111/j.1346-8138.2007.00319.x

[13] Delfino, S., Toto, V., Brunetti, B., Di Marino, M.P., Baldi, A. and Persichetti, P. (2007) Poroid Hidradenoma: A Case Report. In Vivo, 21, 905-907.

[14] Kazakov, D.V., Kutzner, H., Spagnolo, D.V., Kempf, W., Zelger, B., Mukensnabl, P. and Michal, M. (2008) Sebaceous Differentiation in Poroid Neoplasms: Report of 11 Cases, including a Case of Metaplastic Carcinoma Associated with Apocrine Poroma (Sarcomatoid Apocrine Porocarcinoma). American Journal of Dermatopathology, 30, 21-26. http://dx.doi.org/10.1097/DAD.0b013e31815f2ae3

[15] Chiu, H.H., Lan, C.C., Wu, C.S., Chen, G.S., Tsai, K.B. and Chen, P.H. (2008) A Single Lesion Showing Features of Pigmented Eccrine Poroma and Poroid Hidradenoma. Journal of Cutaneous Pathology, 35, 861-865. http://dx.doi.org/10.1111/j.1600-0560.2007.00909.x

[16] Piana, S. and Tagliavini, E. (2010) Papillary Poroid Hidradenoma. American Journal of Dermatopathology, 32, 101102. http://dx.doi.org/10.1097/DAD.0b013e3181a87c51

[17] Goksugur, N. and Yilmaz, F. (2011) Poroid Hidradenoma. Acta Dermatovenerologica Croatica, 19, 122-123.

[18] Roodsari, M.R., Abdolghafoorian, H. and Saiedi, M. (2013) Poroid Hidradenoma: A Rare Tumor Entity. Journal of Case Reports, 3, 448-450. http://dx.doi.org/10.17659/01.2013.0102

[19] Hishida, Y., Hanai, J., Matsushita, N., Yonekawa, M., Kobayashi, Y., Kawakami, H., Uchino, N. and Aozasa, K. (1999) Poroid Hidradenoma. Report of a Case with Cytologic Findings on Fine Needle Aspiration. Acta Cytologica, 43, 471474. 